\title{
Optimization and validation of sample preparation for metagenomic sequencing of viruses in clinical samples
}

Dagmara W. Lewandowska', Osvaldo Zagordi ${ }^{1}$ Fabienne-Desirée Geissberger ${ }^{1}$, Verena Kufner ${ }^{1}$, Stefan Schmutz ${ }^{1}$, Jürg Böni ${ }^{1}$, Karin J. Metzner ${ }^{1,2}$, Alexandra Trkola ${ }^{1}$ and Michael Huber ${ }^{1 *}$ (D)

\begin{abstract}
Background: Sequence-specific PCR is the most common approach for virus identification in diagnostic laboratories. However, as specific PCR only detects pre-defined targets, novel virus strains or viruses not included in routine test panels will be missed. Recently, advances in high-throughput sequencing allow for virus-sequence-independent identification of entire virus populations in clinical samples, yet standardized protocols are needed to allow broad application in clinical diagnostics. Here, we describe a comprehensive sample preparation protocol for high-throughput metagenomic virus sequencing using random amplification of total nucleic acids from clinical samples.
\end{abstract}

Results: In order to optimize metagenomic sequencing for application in virus diagnostics, we tested different enrichment and amplification procedures on plasma samples spiked with RNA and DNA viruses. A protocol including filtration, nuclease digestion, and random amplification of RNA and DNA in separate reactions provided the best results, allowing reliable recovery of viral genomes and a good correlation of the relative number of sequencing reads with the virus input. We further validated our method by sequencing a multiplexed viral pathogen reagent containing a range of human viruses from different virus families. Our method proved successful in detecting the majority of the included viruses with high read numbers and compared well to other protocols in the field validated against the same reference reagent. Our sequencing protocol does work not only with plasma but also with other clinical samples such as urine and throat swabs.

Conclusions: The workflow for virus metagenomic sequencing that we established proved successful in detecting a variety of viruses in different clinical samples. Our protocol supplements existing virus-specific detection strategies providing opportunities to identify atypical and novel viruses commonly not accounted for in routine diagnostic panels.

Keywords: Metagenomic sequencing, Clinical samples, Virus diagnostics, Sample preparation

\section{Background}

To date, sequence-specific PCR is the most common approach for virus identification and quantification in diagnostic laboratories as it is highly sensitive, rapid, and cost effective. However, specific PCR requires prior knowledge of the virus sequence, and a separate assay needs to be designed for each individual virus or virus

\footnotetext{
* Correspondence: huber.michael@virology.uzh.ch

'Institute of Medical Virology, University of Zurich, Winterthurerstrasse 190, 8057 Zurich, Switzerland

Full list of author information is available at the end of the article
}

type. Recently, high-throughput or next generation sequencing (NGS) technologies enabled metagenomicbased identification of viruses by sequencing random fragments of all genomes present in a clinical or environmental sample [1-3]. As viral metagenomics is virus-sequence independent, potentially any virus, cultivable or uncultivable, known or novel, can be readily detected and the method can be applied to all types of virus genomes, including single-stranded DNA and RNA. Several research studies have used this technology in recent years to explore the breadth of the 
virome in diverse biological and environmental samples including human and animal feces [4-12], blood [13, 14], animal and human tissues [15-17], and human respiratory tract secretions [18-22] and highlighted the validity of the approach to detect rare and novel viruses.

Despite the numerous promising attempts to apply metagenomics to virology, direct sequencing of nucleic acids obtained from biological samples results in a high background of genetic material mainly derived from the host and bacteria hampering the detection of viruses $[22,23]$. Sample type greatly influences the composition of sequencing reads, and due to the complexity of clinical materials, sample preparation and virus enrichment methods need to be specifically adapted. Common steps in sample preparation for unbiased metagenomic sequencing are virus enrichment, extraction of nucleic acids, reverse transcription, and unbiased amplification.

Various virus enrichment methods for clinical samples have been suggested. Commonly employed methods include filtration, ultracentrifugation, and nuclease treatment [1, 24-31]. These methods rely on the small size of viruses and the stability of their capsid. Several approaches for virus genome amplification do exist: Multiple displacement amplification (MDA) is often used for whole genome amplification [32-34], e.g., in the VIDISCA method for virus discovery [35]. Linkeramplified shotgun library (LASL) was applied for virus sequencing from marine water samples [8]. The anchored random PCR approach, as used in our study, has been frequently used and described in detail in previous studies [16, 36-42].

Here, we tested various conditions and methods for virus enrichment, nucleic acid extraction, and unbiased amplification with the goal to create a sensitive and robust workflow for metagenomic sequencing of clinical samples in virus diagnostics. We spiked several virus types into plasma from healthy donors to cover different classes of viruses: small non-enveloped DNA (Human adenovirus), large enveloped DNA (Human herpesvirus 4/EBV or Human herpesvirus 5/CMV), small nonenveloped RNA virus (Poliovirus), and enveloped RNA virus (influenzavirus A, Additional file 1: Table S1). We validated our approach using a highly multiplexed viral pathogen reagent containing 25 different viruses. Finally, in experiments with different ratios of spiked viruses, we show a good correlation of the relative number of sequencing reads with the virus input.

\section{Methods}

\section{Virus stock production}

Human adenovirus 7, Human poliovirus 1 (strain LSa), and Human herpesvirus 5 (HHV-5, ATCC VR AD 169) were propagated on MRC-5 cells (human fetal lung fibroblasts) obtained from the European Collection of
Cell Cultures (Salisbury, UK). Viruses were cultivated for 14 days, cells were sonicated for $5 \mathrm{~s}$, centrifuged ( $5 \mathrm{~min}$ at $1200 \mathrm{rpm}$ ), and the supernatant harvested and filtered $(0.45 \mu \mathrm{m})$. Human herpesvirus 4 (HHV-4) was propagated on B-95 cells (marmoset B-lymphoblastoid cell line) centrifuged (5 min at $1200 \mathrm{rpm}$ ), and the supernatant harvested and filtered $(0.45 \mu \mathrm{m})$. Influenzavirus A/WSN/33 was propagated on A549 cells (human alveolar basal epithelial cells) and Influenzavirus A/H1N1/ PR8 on MDCK cells (canine kidney epithelial cells) for up to 4 days, and the supernatants were centrifuged $(10 \mathrm{~min}$ at $1200 \mathrm{rpm})$. Aliquots were stored at $-80^{\circ} \mathrm{C}$.

\section{Virus quantification by quantitative real-time PCR (qPCR)} Viral loads in spiked samples and amplicon concentrations after random amplification were determined by qPCR as described previously for HHV-5 [43], poliovirus [44], adenovirus [45], and influenzavirus (CDC protocol of real-time RT-PCR for swine influenza A H1N1, 28 April 2009). For HHV-4, real-time PCR was performed as described previously [46], but with modified primers (CTTCTCAGTCCAGCGCGTTT and CAGTGGTCCC CCTCCCTAGA) and a modified probe (FAM-CGTAA GCCAGACAGCAGCCAATTGTCAG-TAMRA). All reactions were performed on a ViiA7 Real-Time PCR System (Life Technologies/Thermo Fisher Scientific, Waltham, MA) with the TaqMan RNA-to-Ct 1-Step Kit. One-microliter template (out of $25-\mu \mathrm{l}$ extraction eluate or $50-\mu \mathrm{l}$ amplification reaction, respectively) was used with $10-\mu \mathrm{l}$ master mix, $0.25 \mu \mathrm{M}$ of each primer, $0.125 \mu \mathrm{M}$ probe in a total volume of $20 \mu \mathrm{l}$. Each sample was tested in duplicates with the following cycling conditions: $30 \mathrm{~min}$ at $48{ }^{\circ} \mathrm{C}, 10 \mathrm{~min}$ at $95{ }^{\circ} \mathrm{C}, 50$ cycles of $15 \mathrm{~s}$ at $95^{\circ} \mathrm{C}$, and $1 \mathrm{~min}$ at $60^{\circ} \mathrm{C}$.

\section{Absolute virus quantification by digital PCR}

For experiments using different ratios of virus input, virus stocks were quantified by digital PCR using the QuantStudio 3D Digital PCR System (Life Technologies/ Thermo Fisher Scientific), which allows for absolute quantification without the need of a standard. Reactions were performed in a final volume of $15 \mu \mathrm{l}$ with $7.5 \mu \mathrm{l} 2 \times$ QuantStudio 3D Digital PCR Master Mix, $0.25 \mu \mathrm{M}$ of each primer and $0.125-\mu \mathrm{M}$ probe (same primer and probes as used in the qPCR assays described above). The template was diluted as necessary for optimal digital PCR readout. For RNA virus quantification, the reaction additionally contained $0.4 \mu \mathrm{l} 40 \times$ TaqMan RT Enzyme Mix and an initial reverse transcription step for $15 \mathrm{~min}$ at $48{ }^{\circ} \mathrm{C}$ followed by $10 \mathrm{~min}$ at $96^{\circ} \mathrm{C}$. Cycling conditions were 50 cycles of $2 \mathrm{~min}$ at $60{ }^{\circ} \mathrm{C}, 30 \mathrm{~s}$ at $98{ }^{\circ} \mathrm{C}$, and $60^{\circ} \mathrm{C}$ for $2 \mathrm{~min}$. After read-out on the QuantStudio 3D Digital PCR instrument, the raw data was imported into 
QuantStudio 3D AnalysisSuite Cloud Software (version 3.0.2.2) to calculate absolute copy numbers.

\section{Virus spike preparation and sample pre-processing}

Human clinical samples were obtained from healthy blood donors (Zurich blood donor service, Schlieren, Switzerland) or from diagnostic samples (tested negative for poliovirus, HHV-4, HHV-5, influenzavirus A, and adenovirus) and stored at $-20{ }^{\circ} \mathrm{C}$. Samples were centrifuged at $2000 \mathrm{rpm}$ for $10 \mathrm{~min}$ (Heraeus Multifuge X3 R, Thermo Fisher Scientific), spiked with viruses to achieve quantitative PCR threshold cycles (ct values) of 22-25, which are considered as high positive samples in diagnostic tests for most viruses. Filtration was done using a $0.45-\mu \mathrm{m}$ PES filter (TPP, Trasadingen, Switzerland). Freeze-thaw cycles, if applicable, were performed by freezing the samples at $-20^{\circ} \mathrm{C}$.

\section{Nuclease treatment}

Nuclease treatment with DNase and RNase was performed as previously described [47] with reagent volumes scaled up for $1000 \mu \mathrm{l}$ of clinical sample. Briefly, a nuclease mix containing $120 \mu \mathrm{l}$ DNase $(0.92 \mathrm{mg} / \mathrm{ml}$, Roche, Basel, Switzerland), $10 \mu \mathrm{l}$ RNaseA $(0.77 \mathrm{mg} / \mathrm{ml}$, Qiagen, Hilden, Germany), $130 \mu \mathrm{l} 10 \times$ nuclease buffer ( $400 \mathrm{mM}$ Tris- $\mathrm{HCl}$, $100 \mathrm{mM} \mathrm{NaCl}, 60 \mathrm{mM} \mathrm{MgCl} 2,10 \mathrm{mM} \mathrm{CaCl}$; $\mathrm{pH} 7.9$ ), $30 \mu \mathrm{l}$ PBS, and $10-\mu \mathrm{l}$ water was added. The reaction was incubated for $1 \mathrm{~h}$ at $37^{\circ} \mathrm{C}$ in a thermoshaker at $1400 \mathrm{rpm}$. Samples were treated with protease $(0.71 \mathrm{mg} / \mathrm{ml}$, Qiagen $)$ for $30 \mathrm{~min}$ at $37^{\circ} \mathrm{C}$ to remove nuclease activity.

\section{Nucleic acid extraction}

QIAamp Viral RNA Mini Kit (Qiagen), PureLink Viral RNA/DNA Mini Kit (Life Technologies/Thermo Fisher Scientific), and NucliSENS EasyMAG system (BioMérieux, Craponne, France) were used according to the manufacturer's instructions. Two input volumes of spiked plasma were tested, 500 and $1000 \mu \mathrm{l}$, and eluted into $25 \mu \mathrm{l}$ to achieve a high sample concentration. Large starting volumes were loaded into the extraction columns in multiple steps according to the manufacturer's instructions, if necessary.

\section{Unbiased nucleic acid amplification: combined and separate protocols}

In a first protocol for unbiased nucleic acid amplification [38], we processed RNA and DNA viruses combined in a single reaction, called here the "combined protocol." We changed our protocol to include separate amplification steps for RNA and DNA and replace T7 polymerase with DNA Polymerase I Large Klenow Fragment (NEB Biolabs, Ipswich, MA), called the "separate protocol" [9, 42]. For a direct comparison, Klenow fragment was used for both workflows.
For the RNA workflow, cDNA was generated by reverse transcription with a primer containing a random octamer linked to an anchor sequence ATCGTCGTCGT AGGCTGCTCNNNNNNNN [16, 36, 37]. Five microliters of eluate was used as template in a total volume of $20 \mu \mathrm{l}$, with $5 \mu \mathrm{M}$ of random primer, $1 \mathrm{mM}$ of dNTPs, $1 \times$ first strand buffer, $20 \mathrm{mM}$ DTT, and $20 \mathrm{U} / \mu \mathrm{l}$ of SuperScript III (Invitrogen/Life Technologies). The template and random primers were heated at $65{ }^{\circ} \mathrm{C}$ for $5 \mathrm{~min}$, followed by reverse transcription at $42{ }^{\circ} \mathrm{C}$ for $60 \mathrm{~min}$ and inactivation at $96{ }^{\circ} \mathrm{C}$ for $5 \mathrm{~min}$. Prior to second strand synthesis, cDNA was denatured at $94{ }^{\circ} \mathrm{C}$ for 2 min and cooled down to $10{ }^{\circ} \mathrm{C}$ for $5 \mathrm{~min}$. The second strand was synthesized with $5 \mathrm{U} / \mu \mathrm{l}$ DNA Polymerase I (Klenow) in 10× NEB buffer in a final volume of $10 \mu \mathrm{l}$, at $37{ }^{\circ} \mathrm{C}$ for $30 \mathrm{~min}$ followed by an enzyme inactivation step at $75{ }^{\circ} \mathrm{C}$ for $20 \mathrm{~min}$. An additional step of second strand synthesis used in the initial, combined protocol was omitted.

The DNA workflow started at the denaturation step at $94{ }^{\circ} \mathrm{C}$ for $2 \mathrm{~min}$ and was performed with the same random primer as used in the RNA workflow prior to second strand synthesis. Second strand synthesis was performed using the same conditions as described for the RNA workflow. Further amplification with the anchor primer and AmpliTaq Gold (Thermo Fisher Scientific) was performed as previously described [38], but separately for the RNA and DNA workflow.

\section{High-throughput sequencing and bioinformatic analysis}

The quality and size of the anchor PCR products were assessed by capillary gel electrophoresis (Fragment Analyzer, Advanced Analytical, Ames, IA). PCR products were quantified with PicoGreen (Invitrogen/Thermo Fisher Scientific) and diluted to $0.2 \mathrm{ng} / \mu \mathrm{l}$. DNA and RNA preparations were pooled in equal concentrations for constructing sequencing libraries with the NexteraXT protocol (Illumina, San Diego, CA). Individual samples were dual indexed during the library preparation and pooled for sequencing. Libraries were sequenced on a MiSeq (Illumina) for $1 \times 150$ cycles with version 3 reagents and the "FASTQ only" workflow. Samples were demultiplexed using MiSeq Reporter v2.4.60. Raw sequencing reads are available from the Zenodo repository (10.5281/zenodo.814807). Reads were processed with a dedicated bioinformatic pipeline "VirMet" version 0.3.3 developed in our laboratory (https://github.com/ozagordi/ VirMet/releases/tag/v0.3.3) [38]. Briefly, reads were quality-filtered by removing low quality bases (average PHRED score below 20), reads shorter than 75 bp and reads with low entropy (i.e., consisting mainly of repeats). Read passing quality filters were cleaned from non-viral reads by aligning with STAR $[48,49]$ against, in this order, human, bacterial, bovine, and canine genomes. Reads not 
matching any of the above genomes were aligned with BLAST [50] against an in-house viral database that contains approximately 46,000 different virus sequences. For each sequencing read that passed the quality filter, the BLAST hit with lowest $e$ value was reported, given the identity was higher than $75 \%$. Reads which did not match genomes used in the cleaning step and did not match viral genomes included in the database were reported as of unknown origin.

\section{Analysis of virus enrichment}

Optimization of the protocol was assessed by comparing the virus amplicon concentrations after random amplification by qPCR, by evaluating the fractions of reads of different taxonomic categories after sequencing, and by counting the absolute number of reads and the fraction of the total quality filtered reads for each individual spiked virus. All sequencing experiments were performed in duplicates or triplicates. Statistical analysis was done in $\mathrm{R}$ version 3.3.2 using linear models [51]. Coverage plots for viruses used for spiking were generated by mapping virus reads reported by our VirMet pipeline with smalt (http://www.sanger.ac.uk/science/ tools/smalt-0, default thresholds) against the following reference genomes: Human adenovirus 7 (GenBank AY495969.1), Human poliovirus 1 Mahoney (V01149.1), and HHV-5 strain AD169 (X17403.1).

\section{Results}

\section{Extraction with the NucliSENS EasyMAG resulted in the highest virus concentrations}

First, three different methods of total nucleic acid extraction were tested: QIAamp Viral RNA Mini Kit, PureLink Viral RNA/DNA Mini Kit, and the automated NucliSENS EasyMAG system. Plasma from healthy donors was spiked with different viruses (adenovirus, poliovirus, HHV-4, influenzavirus A) and extracted, and the concentration in the eluate determined by qPCR. EasyMAG extraction was most efficient for both RNA viruses, while virus concentrations for DNA viruses were similar to PureLink extraction. The Qiagen extraction kit led to the lowest recovery of viral genomes for all tested viruses (Additional file 1: Figure S1 and Table S2). Thus, the EasyMAG system was selected as standard extraction method for all further experiments.

\section{Filtration substantially enriches for viruses and decreases non-viral reads}

In order to assess the effect of sample preparation on the sensitivity of metagenomic sequencing, we spiked plasma from healthy donors with both RNA and DNA viruses (poliovirus, adenovirus, and HHV-4). All viruses were spiked at a qPCR threshold cycle (ct value) in the range of 22-25. Different orders of sample processing corresponding to different pre-analytical situations were then tested using the virus-spiked plasma: the condition "same day" extraction comprised filtration, extraction, and short-term storage before further processing at $-20{ }^{\circ} \mathrm{C}$; "pre-processed" comprised filtration, storage at $-80{ }^{\circ} \mathrm{C}$, and later extraction; "archived" samples comprised storage at $-20{ }^{\circ} \mathrm{C}$, filtration, and extraction. In all three conditions, each sample was processed filtered as well as non-filtered.

In all conditions, the fraction of virus reads significantly increased as a result of filtration. Same day extraction with filtration and extraction followed by freezing showed the highest enrichment of virus reads (Fig. 1a).

Considering individual viruses used for spiking, for all three viruses, significantly more reads were reported for filtered samples, both in numbers and in the fraction of total reads passing quality filtering (Fig. 1b, c; Additional file 1: Table S3). Conditions pre-processed and archived (including a freezing step before extraction) proved better for DNA viruses (adenovirus and HHV-4) than "same day extraction". Of note, in all conditions, the highest number of spiked virus reads was reported for poliovirus and the lowest number for HHV-4 (Fig. 1b, c), although the ct values of the input for each virus were similar. For all further samples, we chose pre-processed as standard method.

\section{Nuclease treatment significantly enriches for virus reads} Next, we tested the effect of nuclease treatment, which takes advantage of the presence of a stable virus capsid that protects the viral genome from digestion, in metagenomic sequencing of plasma spiked with two RNA viruses (poliovirus and influenzavirus $\mathrm{A}$ ) and two DNA viruses (adenovirus and HHV-4). Spiked plasma incubated at $4{ }^{\circ} \mathrm{C}$ without reaction buffer and nucleases served as a control.

In samples that were treated with nucleases, we observed an increase in the fraction of reads passing quality filtering (Fig. 2a, Additional file 1: Table S4). This is a result of the digestion of human DNA containing a lot of repetitive (low entropy) sequences and therefore fewer reads to be removed in quality filtering.

With nuclease treatment, reads of viruses increased significantly, while human background reads decreased (Fig. 2b). Freeze/thaw cycles did not improve virus enrichment by nuclease treatment (Fig. 2b).

Considering sequencing reads from the individual viruses, nuclease treatment enriched all viruses, except the large, enveloped DNA virus HHV-5 (Fig. 2c, Additional file 1: Table S5). Incubation alone, without the enriching effect of nuclease treatment, resulted in a reduced recovery of the RNA viruses influenza and polio.

\section{Optimization of unbiased nucleic acid amplification}

In order to optimize unbiased amplification of nucleic acids to represent the entire virus population in a 


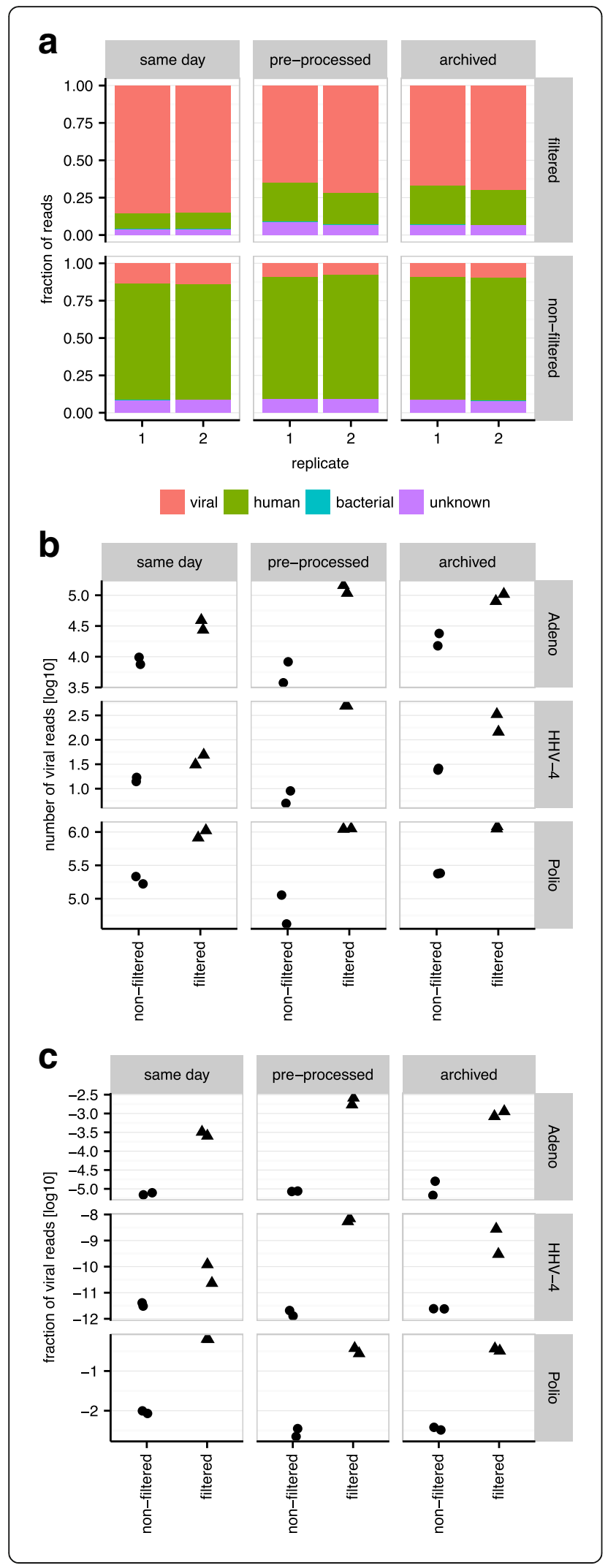

Fig. 1 Filtration substantially enriches for virus reads. Plasma samples were spiked with three different viruses (adenovirus, HHV-4, poliovirus) and prepared under the three following conditions: same day comprised filtration, extraction, and freezing at $-20^{\circ} \mathrm{C}$; pre-processed comprised filtration, freezing at $-80^{\circ} \mathrm{C}$, and extraction; archived included freezing at $-20^{\circ} \mathrm{C}$, filtration, and extraction. All conditions were tested with and without filtration. The experiment was performed in duplicates. a Distribution of sequencing reads into the taxonomic categories viral, human, bacterial, and unknown origin. b Number of reads obtained for each individual virus. c Fraction of all quality passing reads obtained for each individual virus

sample, we divided the workflow to process RNA and DNA in two separate reactions and changed the enzyme for second strand synthesis from T7 DNA polymerase to Klenow Large Fragment [42]. For comparison, sample volumes were kept identical for both workflows. Using qPCR after random PCR amplification, higher amplicon concentrations were obtained for DNA viruses processed in the separate DNA workflow, when compared to the combined protocol (data not shown). After sequencing, the fraction of virus reads was enriched in the separate protocol for DNA when compared to the combined reaction as well (Fig. 3a). Most importantly, higher numbers of sequencing reads were obtained for all viruses in the separate workflows compared to the combined workflow, especially also for HHV-4 and influenzavirus (Fig. 3b, Additional file 1: Table S6).

As shown before [30], sample preparation can influence the coverage of viral genomes. We therefore aligned virus reads reported by the combined and separate workflow for each virus to its reference genome. Reads were uniformly distributed along the reference genomes in both workflows (Additional file 1: Figure S2).

We further tested if a higher input volume into the reverse transcription reaction and the downstream anchor PCR would increase virus recovery. Using the separate protocol, input strategy 1 used $5 \mu \mathrm{l}$ of the extract into the reverse transcription reaction and $3 \mu \mathrm{l}$ of the reverse transcription reaction into the anchor PCR; input strategy 2 used double the amount (10 and $6 \mu \mathrm{l}$, respectively). Viral amplicon concentrations after the anchor PCR were higher for input strategy 2 (Additional file 1: Figure S3A). However, the fraction of virus reads and reads assigned to each spiked virus were at similar levels for both input strategies (Additional file 1: Figure S3B and S3C, Additional file 1: Table S7).

Our final workflow is depicted in Fig. 4.

The optimized metagenomic sequencing protocol detects the majority of virus species in a highly multiplexed viral pathogen reagent

After establishing a workflow for unbiased, metagenomic sequencing using spiked plasma samples, we used our 


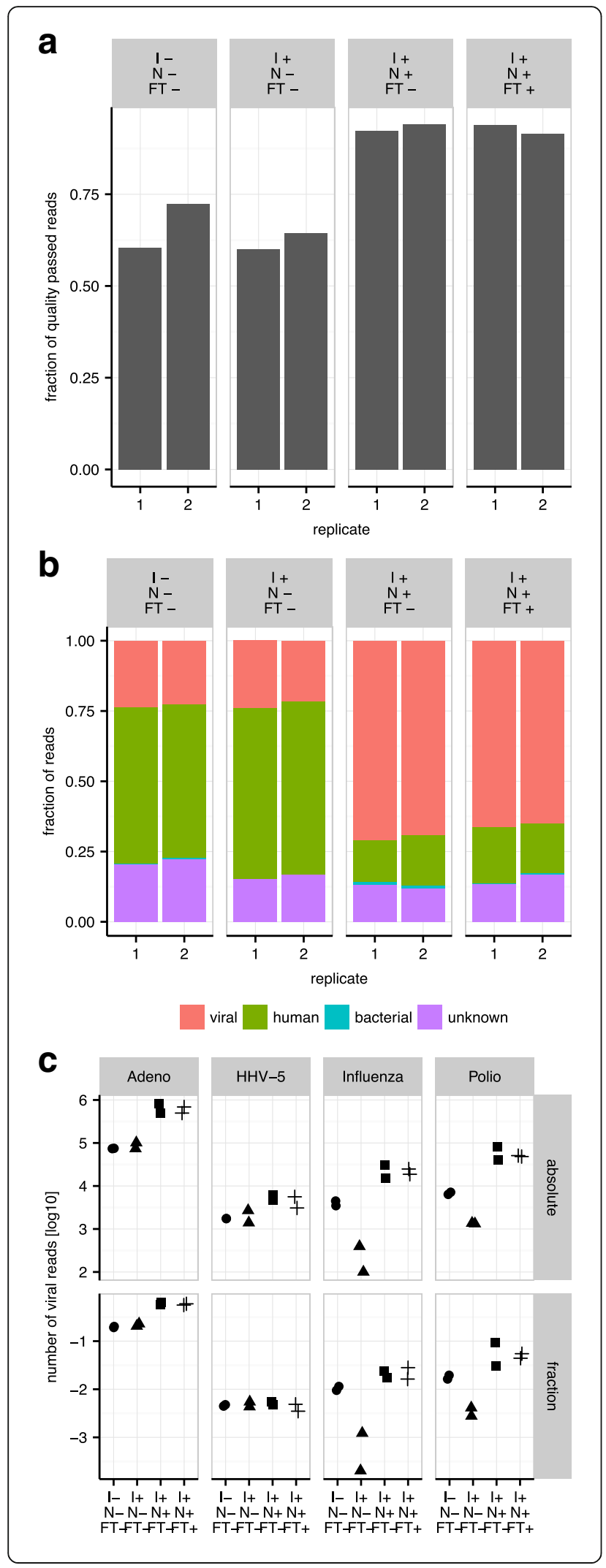

Fig. 2 Nuclease treatment significantly enriches for virus reads. To test nuclease treatment in metagenomic sequencing, plasma samples were spiked with four different viruses (adenovirus, $\mathrm{HHV}-5$, influenzavirus, poliovirus) and processed with and without incubation at $37^{\circ} \mathrm{C}$ $(\mathrm{I}+/-)$, nuclease treatment $(\mathrm{N}+/-)$ and freeze-thaw cycles (FT $+/-)$, respectively. The experiment was performed in duplicates. a Fraction of sequencing reads that passed quality filtering. $\mathbf{b}$ Distribution of sequencing reads into the different taxonomic categories viral, human, bacterial, and unknown origin. c Number of reads (upper panels) and fraction of all quality passing reads (lower panels) obtained for each individual virus

new protocol for testing a highly multiplexed viral pathogen reagent (11/242-001, National Institute for Biological Standards and Control, South Mimms, UK) containing 25 different human viruses from different virus families [52] (Table 1). We processed and sequenced $1000 \mu \mathrm{l}$ of the reagent. As our bioinformatic pipeline VirMet determines the taxonomic origin of each individual read, we summed up reads at the species level and noted the most commonly reported strain. Of the 25 viruses expected in the reagent, we detected 17 and 15 different viruses in two replicates, respectively, with high numbers of reads (Table 1). Previous studies have sequenced the same viral pathogen reagent $[30,52]$. We randomly subsampled our raw reads to match the numbers analyzed in these studies. Using 2,000,000 reads, we still detected 17 viruses in one of the replicates. Seven of the eight viruses we did not detect (Coronavirus 229E, Norovirus GI and GII, Influenzavirus A and B, Human parainfluenza virus 3) were missed by 15 to $79 \%$ of other methods as well [52]. Comparing our results to similar workflows (filtration, nuclease treatment, random amplification, NexteraXT, MiSeq) as, for instance, the sample preparation methods $\mathrm{N} 1-\mathrm{N} 4$ presented in $\mathrm{Li}$ et al. [30], our numbers of reads were higher as reported and we identified more virus species (Table 1, 150,000 reads). As previously shown, additional non-targeted viruses are present in the reagent and were detected by us as well (e.g., Bovine viral diarrhea virus, Bocavirus, Enterovirus; Table 1).

\section{Ratio of virus reads correlates with concentration of viruses in spiked plasma}

In order to confirm that our protocol detects viruses in a reproducible and quantitative manner, we sequenced plasma samples spiked with different ratios and concentrations of an RNA virus (poliovirus or influenzavirus) and a DNA virus (adenovirus). First, we spiked a concentration of 50,000 copies/ $\mu \mathrm{l}$ of both viruses; we then spiked ten times more and ten times less of one virus while keeping the other virus constant at 50,000 copies/ $\mu \mathrm{l}$, and vice versa for the other virus.

After extraction, viral amplicons were quantified in the eluate and the ratio of spiked viruses was perfectly 

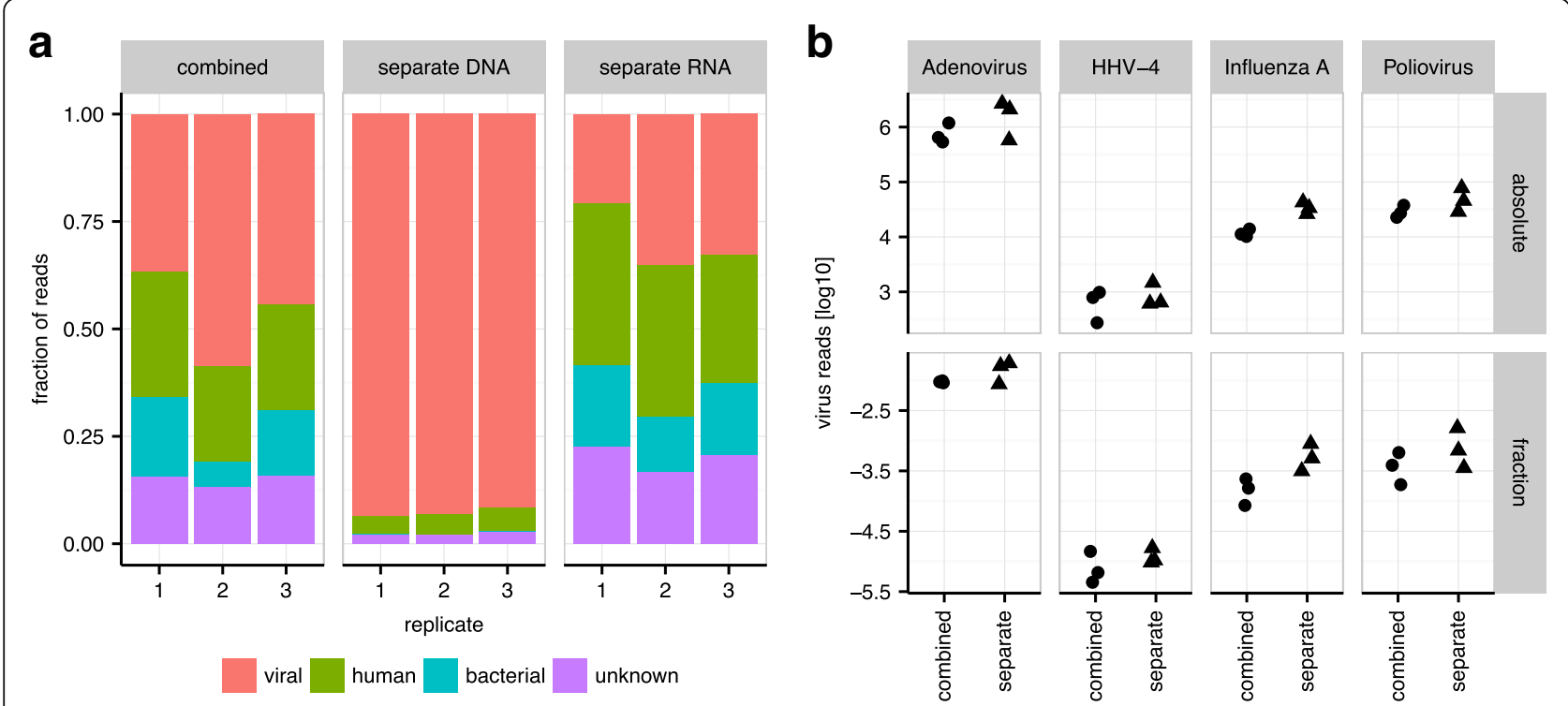

Fig. 3 Separate workflows for RNA and DNA yielded higher sequencing reads for DNA viruses. Plasma samples were spiked with four different viruses (adenovirus, HHV-4, influenzavirus, poliovirus) and processed and sequenced with the combined and the new separate workflow. In the separate workflow, random amplification products were pooled before NexteraXT library preparation in equal concentrations. The experiment was performed in triplicates. a Distribution of sequencing reads into the different taxonomic categories viral, human, bacterial, and unknown origin. b Number of reads (upper panels) and fraction of all quality passing reads (lower panels) obtained for each individual virus

maintained (Additional file 1: Figure S4). After random amplification and sequencing with the separate workflow, we calculated the ratio of the number of reads of the two viruses, as the number of total reads in each sample varied and the viruses are amplified differentially. The ratio of the virus reads in a sample correlated well with the difference in ct values in the initial sample, showing that our method amplifies and detects both viruses in a reproducible and quantitative manner (Fig. 5).

Sample preparation of clinical samples other than plasma In order to test if our method established with plasma also works for other clinical samples, we spiked the same volume of plasma, urine, throat swab, and two different stool suspensions with the same amount of viruses. After sequencing, the fraction of virus reads in urine and throat swab was similar as for plasma (Fig. 6, Additional file 1: Table S8). For stool samples, however, the amount of unknown background reads was substantially higher and virus reads, if detected, were mostly bacteriophages. For the individual viruses that were spiked, the number and fraction of virus reads were significantly decreased in both stool samples. A more stringent virus enrichment protocol is therefore needed to sequence stool samples to achieve the same sensitivity $[53,54]$.

\section{Discussion}

In this study, we developed and validated a sample preparation protocol for unbiased amplification and highthroughput metagenomic sequencing of viruses in routine diagnostic use. In an unbiased metagenomic approach, prior knowledge of the virus sequence is not required. In principle, it can therefore detect any virus. However, sample processing needs to be optimized for recovery and amplification of viral genomes that might be present only in very small amounts in clinical samples. We optimized such a protocol using plasma samples spiked with different classes of viruses.

First, we tested filtration, extraction, and nuclease digestion procedures in order to find optimal conditions for virus enrichment and reduction of unwanted, nonviral reads. Filtration proved to be indispensable, as the number of virus reads after sequencing significantly increased. Additionally, sample pre-processing including a freeze thaw cycle showed the best enrichment (Fig. 1), and for best integration into the daily laboratory workflow, we chose pre-processed for further experiments. Two of the extraction methods tested here have been compared before with a higher scoring for the QIAamp Viral RNA Mini Kit compared to the PureLink Viral RNA/DNA Mini Kit [27]. Other studies reported limited coverage of the genome using a magnetic bead-based method similar in principle to the EasyMAG [30]. However, we did not observe this as we obtained good coverage of the entire genome (Additional file 1: Figure S2).

Nuclease treatment, which takes advantage of the stable virus capsid that shields the viral genome from digestion, significantly reduced the fraction of human reads and increased the amount of reads passing the quality filter in our analysis pipeline. This is a result of 


\section{Centrifugation}

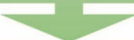

\section{Filtration $(0.45 \mu \mathrm{m})$}

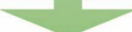

\section{Storage $\left(-80^{\circ} \mathrm{C}\right)$}

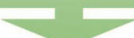

Nuclease treatment

$+2$

Nucleic acid extraction (EasyMAG)

RNA

cDNA synthesis

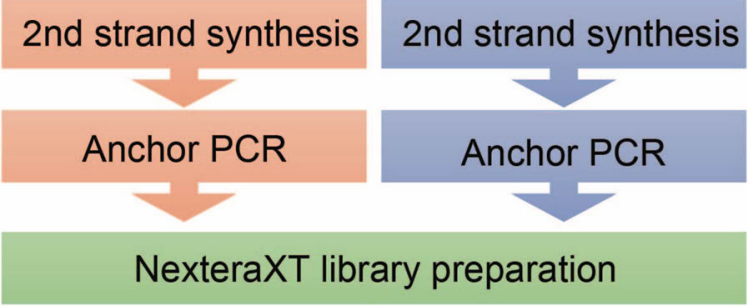

Fig. 4 Optimized workflow for metagenomic virus sequencing. A workflow for metagenomic virus sequencing for diagnostic use was developed. Sample pre-processing included low-speed centrifugation, $0.45-\mu \mathrm{m}$ filtration, storage at $-80^{\circ} \mathrm{C}$, and DNase and RNase digestion. Random reverse transcription with an $8 \mathrm{~N}$ primer including an anchor sequence, second strand synthesis, and anchor PCR amplification was performed separately for an RNA and DNA workflow. The two workflows were pooled in equal concentration for library preparation with NexteraXT

the digestion of human DNA containing high numbers of repetitive (low entropy) sequences and important for maximizing the amount of quality reads to increase sensitivity. Nuclease treatment enriched for all viruses, except HHV-5, which might, probably due to its size or envelope, not be as stable as smaller viruses. While the combination of low-speed centrifugation, filtration, and nuclease-treatment also showed the greatest increase in the proportion of viral sequences in other studies [29] and filtration and DNase treatment lead to dramatic improvements [25], some studies only found minor differences among the methods with or without filtration and nuclease digestion [30]. The reason for these discrepancies might be that some studies compare pre-sequencing nucleic acid concentrations while others compare sequencing reads. Enrichment methods in general decrease the absolute concentration; however, in our hands, the overall gain of nuclease treatment to increase the ratio of virus over host prevails.

Poliovirus reads were recovered in highest numbers in our experiments, although the amount of spiked viruses was adjusted to similar levels (ct values). This might be due to the fact that poliovirus has the smallest virion and genome size among the spiked viruses, what might have facilitated its efficient enrichment and amplification. In contrast, HHV-4 virus is a large virus in respect to virion and genome size and often only single reads could be detected. It was suggested that filtration might actually have an adverse effect on large virus genomes such as herpesvirus and mimivirus [28]. In other studies of virus profiling in clinical specimens, lower numbers of HHV-4 reads as expected were also reported [55]. However, experiments using HHV-5, which belongs to the same virus family as HHV-4, resulted in many more virus reads. Therefore, it is conceivable that other factors than virus and genome size are influencing the number of recovered viral genomes.

Separating the random amplification into two separate workflows for RNA and DNA was more advantageous for the DNA viruses than for the RNA viruses. This could be either a result of concomitant amplification of DNA viruses in the RNA workflow or an indication that DNA genome amplification was negatively affected during the reverse transcription and second strand synthesis in the previous combined workflow. Yet, for both the combined and separate workflow, reads were uniformly distributed across the reference genomes and we did not observe differences.

In order to validate our method, we sequenced a multiplexed viral pathogen reagent that was expected to contain 25 viruses across different families, genome types, and sizes [52]. At most, we identified 17 different viruses (Table 1). We did not detect any reads for eight viruses supposed to be in the reagent, all of them singlestranded RNA viruses (Coronavirus 229E, Norovirus GI and GII, Influenzavirus A and B, Metapneumovirus, $\mathrm{Hu}-$ man Parainfluenzavirus 3). However, most of these viruses were present at very low concentration in the viral pathogen reagent (undetectable by qPCR after mixing of the reagent) and were also frequently not detected by other groups that probed this reagent. In the study by Mee et al. [52], a wide range of different sample volumes and enrichment, amplification, and sequencing methods were used. Stochastic effects in detection of very low abundant viruses and differences in analysis thresholds could have played a role as well. Comparing our results to more similar workflows (filtration, nuclease treatment, random amplification, NexteraXT, MiSeq), our numbers of reads were higher than reported and we 
Table 1 Number of reads reported from sequencing a multiplexed viral pathogen reagent

\begin{tabular}{|c|c|c|c|c|c|c|}
\hline \multirow[b]{2}{*}{ Virus species (most frequent strain) } & \multicolumn{3}{|l|}{ Replicate 1} & \multicolumn{3}{|l|}{ Replicate 2} \\
\hline & $\begin{array}{l}\text { All 3,505,318 } \\
\text { reads }\end{array}$ & $\begin{array}{l}2,000,000 \\
\text { reads }\end{array}$ & $\begin{array}{l}150,000 \\
\text { reads }\end{array}$ & $\begin{array}{l}\text { All 2,676,604 } \\
\text { reads }\end{array}$ & $\begin{array}{l}2,000,000 \\
\text { reads }\end{array}$ & $\begin{array}{l}150,000 \\
\text { reads }\end{array}$ \\
\hline \multicolumn{7}{|l|}{25 target viruses } \\
\hline Human astrovirus (Human astrovirus 1) & 27,622 & $15,783.2$ & 1184.1 & 8040.6 & 596.2 & 8040.6 \\
\hline Enterovirus B (Human coxsackievirus B4) & 27,252 & $15,539.0$ & 1161.3 & $22,707.3$ & 1704.4 & $22,707.3$ \\
\hline Human herpesvirus 1 & 67 & 39.0 & 3.5 & 81.4 & 5.5 & 81.4 \\
\hline Human herpesvirus 2 & 2 & 1.3 & 0.4 & 7.0 & 0.4 & 7.0 \\
\hline Human herpesvirus 3 (Human herpesvirus 3 strain Dumas) & 34 & 17.4 & 1.4 & 84.2 & 6.4 & 84.2 \\
\hline Human herpesvirus 4 & 166 & 98.1 & 8.2 & 104.7 & 8.7 & 104.7 \\
\hline Human herpesvirus 5 & 8327 & 4743.1 & 352.1 & 7028.5 & 524.4 & 7028.5 \\
\hline Human mastadenovirus C (Human adenovirus 2) & 23 & 11.5 & 0.8 & 299.1 & 19.6 & 299.1 \\
\hline Human mastadenovirus F (Human adenovirus 41) & 2 & 2.0 & 0.0 & 13.9 & 1.7 & 13.9 \\
\hline Human metapneumovirus & 0 & 0.0 & 0.0 & 0.0 & 0.0 & 0.0 \\
\hline Human parainfluenza virus 1 & 21,387 & $12,170.8$ & 921.2 & 9601.2 & 718.6 & 9601.2 \\
\hline Human parainfluenza virus 2 & 2879 & 1651.5 & 119.6 & 33.1 & 1.6 & 33.1 \\
\hline Human parainfluenza virus 3 & 0 & 0.0 & 0.0 & 0.0 & 0.0 & 0.0 \\
\hline Human parainfluenza virus 4 (Human parainfluenzavirus 4b) & 21,858 & $12,478.6$ & 924.3 & $10,089.8$ & 760.2 & $10,089.8$ \\
\hline Human respiratory syncytial virus & 0 & 0.0 & 0.0 & 229.4 & 15.5 & 229.4 \\
\hline Human Rhinovirus A (Human rhinovirus A39) & 0 & 0.0 & 0.0 & 2238.4 & 158.6 & 2238.4 \\
\hline Influenzavirus A H1N1 & 0 & 0.0 & 0.0 & 0.0 & 0.0 & 0.0 \\
\hline Parechovirus A (Human parechovirus 3) & $1,492,756$ & $851,560.6$ & $63,862.7$ & $565,228.5$ & $42,434.5$ & $565,228.5$ \\
\hline Rotavirus A & 6 & 2.8 & 0.3 & 8.5 & 0.8 & 8.5 \\
\hline $\begin{array}{l}\text { Sapporovirus (Sapovirus Hu/GI.2/BR-DF01/BRA/2009 } \\
\text { and Hu/G1/BE-HPI01/DE/2012) }\end{array}$ & 1019 & 575.5 & 45.2 & 62.8 & 5.1 & 62.8 \\
\hline Human coronavirus 229E & 0 & 0.0 & 0.0 & 0.0 & 0.0 & 0.0 \\
\hline Norovirus Gl & 0 & 0.0 & 0.0 & 0.0 & 0.0 & 0.0 \\
\hline Norovirus Gll & 0 & 0.0 & 0.0 & 0.0 & 0.0 & 0.0 \\
\hline Influenza virus B & 0 & 0.0 & 0.0 & 0.0 & 0.0 & 0.0 \\
\hline Influenza virus A H3N2 & 0 & 0.0 & 0.0 & 0.0 & 0.0 & 0.0 \\
\hline \multicolumn{7}{|l|}{ Non-target viruses } \\
\hline Bovine viral diarrhea virus 1 & 1446 & 820.6 & 63.6 & 1891.8 & 140.3 & 1891.8 \\
\hline Bovine viral diarrhea virus 2 & 1 & 0.4 & 0.4 & 0.0 & 0.0 & 0.0 \\
\hline Primate bocaparvovirus 1 & 0 & 0.0 & 0.0 & 0.0 & 0.0 & 0.0 \\
\hline Primate bocaparvovirus 2 & 208 & 118.2 & 7.5 & 91.6 & 6.8 & 91.6 \\
\hline Human enterovirus (Enterovirus CA55-1988) & 3199 & 1834.7 & 140.6 & 380.6 & 28.7 & 380.6 \\
\hline Aichi virus & 0 & 0.0 & 0.0 & 0.0 & 0.0 & 0.0 \\
\hline Ungulate bocaparvovirus 1 & 0 & 0.0 & 0.0 & 0.0 & 0.0 & 0.0 \\
\hline Porcine/other circovirus & 0 & 0.0 & 0.0 & 0.0 & 0.0 & 0.0 \\
\hline Total virus reads & $1,608,254$ & $917,448.3$ & $68,797.2$ & 840,888 & $628,222.4$ & $47,138.0$ \\
\hline Number of detected target viruses & 15 & 14.4 & 11.7 & 17 & 17.0 & 15.7 \\
\hline
\end{tabular}

For subsamples of reads, the average number of virus reads and detected target viruses in 10 random samplings is shown

identified more virus species [30]. Therefore, we think that our method, which might still have potential for improved sensitivity, shows no bias against a certain virus family or genome type (e.g., ssRNA).
To assess how robust our sample preparation is, we correlated different ratios of spiked viruses with the number of corresponding sequencing reads. In both virus combinations and experiments performed, there 


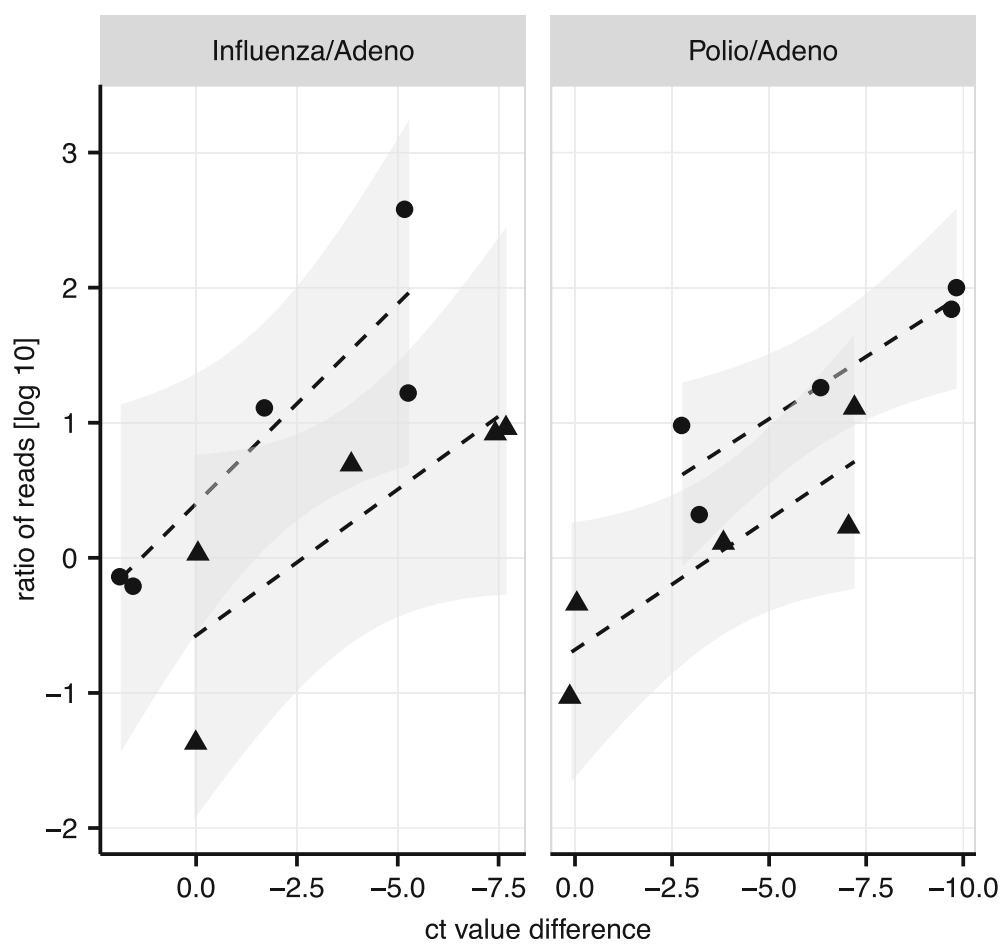

Fig. 5 Ratio of virus reads correlates with concentration of viruses in spiked plasma. Poliovirus/adenovirus and influenzavirus/adenovirus were spiked in healthy donor plasma in different concentrations: at the same concentration for both viruses, ten times more of one virus (keeping the other virus constant) and ten times less of one virus (keeping the other virus constant). The ratio of the sequencing reads for each virus combination was correlated with the concentration ratio (ct value difference) in the input sample. Two independent experiments are shown (circles and triangles, respectively). Shaded areas show the $95 \%$ confidence interval. $R^{2}=0.74,0.59,0.79$, and 0.69 and pvalues $=0.04,0.08,0.02$, and 0.05 for influenza/ adenovirus experiments 1 and 2 and polio/adenovirus experiments 1 and 2, respectively
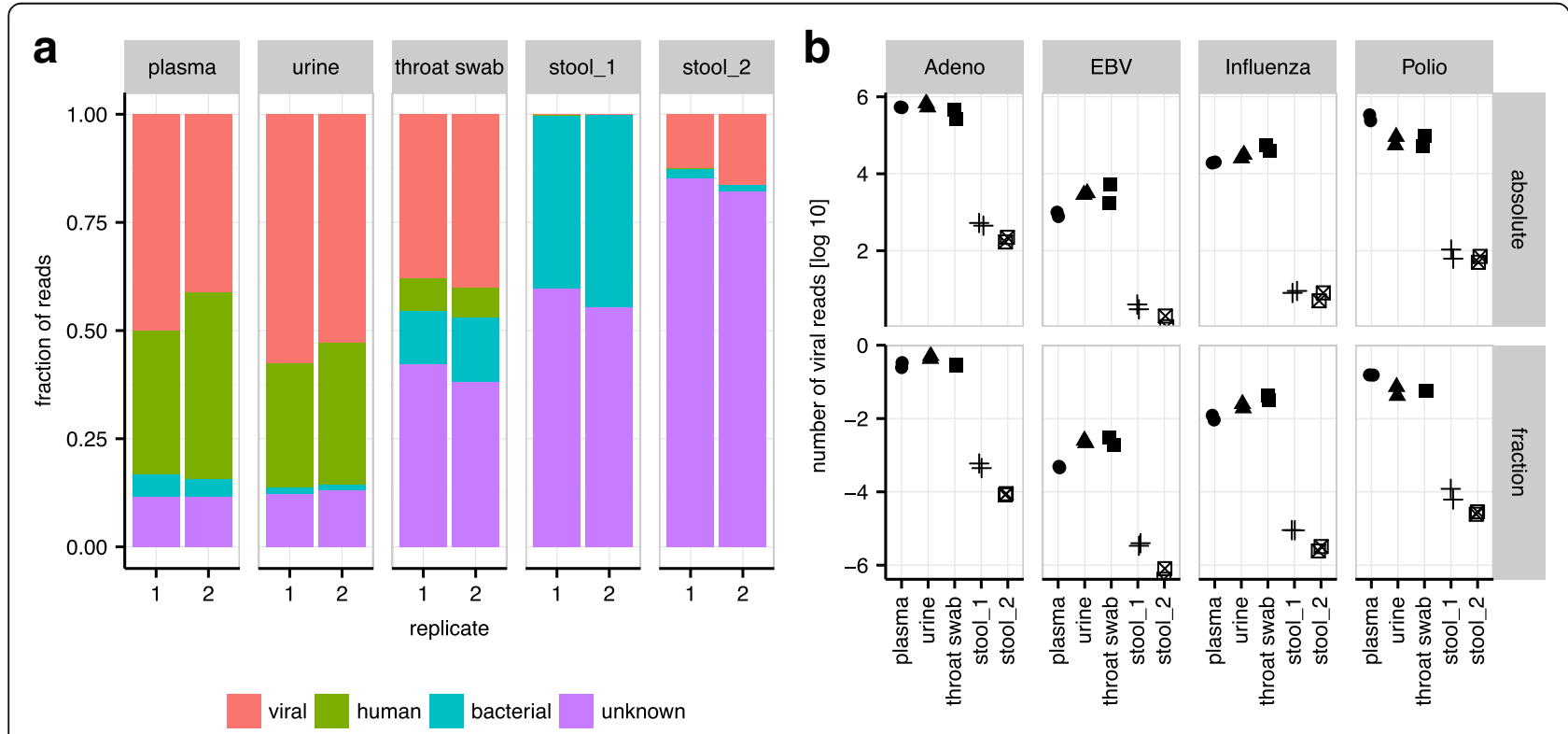

Fig. 6 Sequencing of the same virus spike in different clinical samples. The same volume of plasma, urine, throat swab, and two different stool samples were spiked with the same amount of four different viruses (adenovirus, HHV-4, influenzavirus, poliovirus) and sequenced. The experiment was done in duplicates. a Distribution of sequencing reads into the different taxonomic categories viral, human, bacterial, and unknown origin. b Number of reads (upper panels) and fraction of all quality passing reads (lower panels) obtained for each individual virus 
was a good correlation between the ratio of spiked viruses and the ratio of the resulting reads (Fig. 4). Direct correlations of viral copies with percentages of sequencing reads have been suggested $[18,54]$. However, a direct quantification of input copy numbers based on sequencing reads seems not applicable. Viruses have different properties such as the presence of an envelope, types of genomes, and virion sizes, and certain virus or genome types are amplified preferentially as we have seen with Poliovirus in our experiments. Adding to the complexity, different composition of the genetic background in clinical samples will strongly influence the yield of virus reads. Nevertheless, the correlations showed that the ratio of sequencing reads is preserved over different input ratios and concentrations, signifying that the amplification method itself preserves the relative contribution of different viruses in a sample.

Finally, spiking the same amount of viruses in different samples showed that the protocol presented here could be applied not only for plasma, but also for other clinical samples such as urine and swabs. A more stringent virus enrichment protocol is needed to sequence stool samples or biopsies, as those contain a lot of bacterial or human background reads, respectively $[53,54]$.

\section{Conclusions}

A metagenomic virus sequencing protocol, as presented here, allows diagnostic laboratories to potentially identify any virus present in clinical samples with a single analysis. Such an approach reduces the time and cost spent today on multiple tests performed for each distinct virus and allows detecting rare or novel viruses not accounted for in routine test panels. Characterization of the virome and its alterations in specific disease settings might help to better understand and manage infectious diseases. Finally, our analysis highlights the need for validation methods and standards for metagenomic sequencing approaches in clinical diagnostics.

\section{Additional file}

Additional file 1: Table S1. Characteristics of viruses used in the virusspike experiments. Table S2. Analysis of variance Figure S1 (extraction experiments). Table S3. Analysis of Variance Fig. 1 (filtration experiments). Table S4. Analysis of variance Fig. 2 (nuclease digestion experiments). Table S5. Analysis of variance Fig. 2 (nuclease digestion experiments). Table S6. Analysis of variance Fig. 3 (separate workflow experiments). Table S7. Analysis of variance Figure S3 (input experiments). Table S8. Analysis of variance Fig. 6 (other sample types). Table S9. Raw sequencing data files (available at Zenodo 10.5281/zenodo.814807). Figure S1. Extraction with the NucliSENS EasyMAG resulted in the highest virus concentrations. Figure S2. Reads assigned to spiked virus were uniformly distributed along the reference genomes. Figure S3. Increasing the PCR input volume had no effect on viral enrichment. Figure S4. After extraction, viral amplicons were quantified in the eluate and the ratio of spiked viruses was perfectly maintained. (PDF $540 \mathrm{~kb}$ )

\section{Acknowledgements}

We thank Edward Mee from the NIBSC (South Mimms, Hertfordshire, UK) for providing us with the multiplexed viral pathogen reagent. We thank the IMV Diagnostics team, Merle Schanz, and Silke Stertz for providing virus stocks.

\section{Funding}

Funding was provided by the Clinical Research Priority Program "Viral Infectious Diseases" of the University of Zurich. The funding body did not have any role in the design of the study, in the collection, analysis, and interpretation of data, and in writing the manuscript.

\section{Availability of data and materials}

Raw sequencing data are available on the Zenodo repository (10.5281/ zenodo.814807). The analysis pipeline "VirMet" is available on github (https://github.com/ozagordi/VirMet/releases/tag/v0.3.3).

\section{Authors' contributions}

DWL, AT, and $\mathrm{MH}$ conceived and designed the study. DWL, FDG, VK, and SS performed experiments. DWL, OZ, JB, KJM, and MH analyzed the data. DWL and $\mathrm{MH}$ wrote the manuscript. All authors read, commented on, and approved the final manuscript.

\section{Ethics approval and consent to participate}

Plasma was obtained from anonymous blood donations of healthy individuals at the Zurich Blood Transfusion Service (http://www.zhbsd.ch). Other clinical samples were obtained from anonymized leftovers used for routine diagnostic tests. Research using anonymized biological material is not restricted by the Swiss Federal Act on Research involving Human Beings.

\section{Consent for publication}

Not applicable.

\section{Competing interests}

KJM has received travel grants and honoraria from Gilead Sciences, Merck Sharp \& Dohme, Bristol-Myers Squibb, and ViiV. The University of Zurich received research grants from Gilead Sciences, Merck Sharp \& Dohme, and Roche for studies that KJM served as principal investigator and advisory board honoraria from Gilead Sciences. The other authors declare that they have no competing interests.

\section{Publisher's Note}

Springer Nature remains neutral with regard to jurisdictional claims in published maps and institutional affiliations.

\section{Author details}

${ }^{1}$ Institute of Medical Virology, University of Zurich, Winterthurerstrasse 190, 8057 Zurich, Switzerland. 'Department of Infectious Diseases and Hospital Epidemiology, University Hospital Zurich, Rämistrasse 100, 8091 Zurich, Switzerland.

Received: 7 April 2017 Accepted: 25 July 2017

Published online: 08 August 2017

\section{References}

1. Delwart EL. Viral metagenomics. Rev Med Virol. 2007;17(2):115-31.

2. Mokili JL, Rohwer F, Dutilh BE. Metagenomics and future perspectives in virus discovery. Curr Opin Virol. 2012;2(1):63-77.

3. Smits SL, Osterhaus AD. Virus discovery: one step beyond. Curr Opin Virol. 2013;3(2):e1-e6.

4. Phan TG, Nordgren J, Ouermi D, Simpore J, Nitiema LW, Deng X, Delwart EL. New astrovirus in human feces from Burkina Faso. J Clin Virol. 2014;60(2): $161-4$.

5. Smits SL, Schapendonk CME, van Beek J, Vennema H, Schürch AC, Schipper D, Bodewes R, Haagmans BL, Osterhaus ADME, Koopmans MP. New viruses in idiopathic human diarrhea cases, the Netherlands. Emerg Infect Dis. 2014; 20(7):1218-22

6. Bodewes R, Ruiz-Gonzalez A, Schapendonk CM, van den Brand JM, Osterhaus AD, Smits SL. Viral metagenomic analysis of feces of wild small carnivores. Virol J. 2014;11(1):89. 
7. Finkbeiner SR, Allred AF, Tarr PI, Klein EJ, Kirkwood CD, Wang D. Metagenomic analysis of human diarrhea: viral detection and discovery. PLoS Pathog. 2008;4(2):e1000011.

8. Breitbart M, Hewson I, Felts B, Mahaffy JM, Nulton J, Salamon P, Rohwer F. Metagenomic analyses of an uncultured viral community from human feces. J Bacteriol. 2003;185(20):6220-3.

9. Victoria JG, Kapoor A, Li L, Blinkova O, Slikas B, Wang C, Naeem A, Zaidi S, Delwart EL. Metagenomic analyses of viruses in stool samples from children with acute flaccid paralysis. J Virol. 2009;83(9):4642-51.

10. Finkbeiner SR, Holtz LR, Jiang Y, Rajendran P, Franz CJ, Zhao G, Kang G, Wang D. Human stool contains a previously unrecognized diversity of novel astroviruses. Virol J. 2009;6(161):1-5.

11. Cotten M, Oude Munnink B, Canuti M, Deijs M, Watson SJ, Kellam P, van der Hoek L. Full genome virus detection in fecal samples using sensitive nucleic acid preparation, deep sequencing, and a novel iterative sequence classification algorithm. PLoS One. 2014;9(4):e93269.

12. Moore NE, Wang J, Hewitt J, Croucher D, Williamson DA, Paine S, Yen S, Greening GE, Hall RJ. Metagenomic analysis of viruses in feces from unsolved outbreaks of gastroenteritis in humans. J Clin Microbiol. 2015; 53(1):15-21.

13. Law J, Jovel J, Patterson J, Ford G, O'keefe S, Wang W, Meng B, Song D, Zhang Y, Tian Z, et al. Identification of hepatotropic viruses from plasma using deep sequencing: a next generation diagnostic tool. PLoS One. 2013; 8(4):e60595

14. Rascovan N, Duraisamy R, Desnues C. Metagenomics and the human Virome in asymptomatic individuals. Annu Rev Microbiol. 2016;70:125-41.

15. Johansson H, Bzhalava D, Ekström J, Hultin E, Dillner J, Forslund O. Metagenomic sequencing of "HPV-negative" condylomas detects novel putative HPV types. Virology. 2013;440(1):1-7.

16. Victoria JG, Kapoor A, Dupuis K, Schnurr DP, Delwart EL. Rapid identification of known and new RNA viruses from animal tissues. PLoS Pathog. 2008;4(9): e1000163.

17. Palacios G, Lovoll M, Tengs T, Hornig M, Hutchison S, Hui J, Kongtorp R-T, Savji N, Bussetti AV, Solovyov A, et al. Heart and skeletal muscle inflammation of farmed salmon is associated with infection with a novel reovirus. PLoS One. 2010;5(7):e11487.

18. Prachayang recha S, Schapendonk CME, Koopmans MP, Osterhaus ADME, Schürch AC, Pas SD, van der Eijk AA, Poovorawan Y, Haagmans BL, Smits SL. Exploring the potential of next-generation sequencing in detection of respiratory viruses. J Clin Microbiol. 2014;52(10):3722-30.

19. Fischer $N$, Indenbirken $D$, Meyer T, Lütgehetmann M, Lellek H, Spohn M, Aepfelbacher M, Alawi M, Grundhoff A. Evaluation of unbiased next-generation sequencing of RNA (RNA-seq) as a diagnostic method in influenza viruspositive respiratory samples. J Clin Microbiol. 2015;53(7):2238-50.

20. Willner D, Furlan M, Haynes M, Schmieder R, Angly FE, Silva J, Tammadoni S, Nosrat B, Conrad D, Rohwer F. Metagenomic analysis of respiratory tract DNA viral communities in cystic fibrosis and non-cystic fibrosis individuals. PLoS One. 2009;4(10):e7370.

21. Lysholm F, Wetterbom A, Lindau C, Darban H, Bjerkner A, Fahlander K Lindberg AM, Persson B, Allander T, Andersson B. Characterization of the viral microbiome in patients with severe lower respiratory tract infections, using metagenomic sequencing. PLoS One. 2012;7(2):e30875.

22. Yang J, Yang F, Ren L, Xiong Z, Wu Z, Dong J, Sun L, Zhang T, Hu Y, Du J, et al. Unbiased parallel detection of viral pathogens in clinical samples by use of a metagenomic approach. J Clin Microbiol. 2011;49(10):3463-9.

23. Mokili JL, Dutilh BE, Lim YW, Schneider BS, Taylor T, Haynes MR, Metzgar D, Myers CA, Blair PJ, Nosrat B, et al. Identification of a novel human papillomavirus by metagenomic analysis of samples from patients with febrile respiratory illness. PLoS One. 2013;8(3):e58404.

24. Cann AJ, Fandrich SE, Heaphy S. Analysis of the virus population present in equine faeces indicates the presence of hundreds of uncharacterized virus genomes. Virus Genes. 2005;30(2):151-6.

25. Allander T, Emerson SU, Engle RE, Purcell RH, Bukh J. A virus discovery method incorporating DNase treatment and its application to the identification of two bovine parvovirus species. Proc Natl Acad Sci. 2001; 98(20):11609-14.

26. Thurber RV, Haynes M, Breitbart M, Wegley L, Rohwer F. Laboratory procedures to generate viral metagenomes. Nat Protoc. 2009;4(4):470-83.

27. Kohl C, Brinkmann A, Dabrowski PW, Radonić A, Nitsche A, Kurth A. Protocol for metagenomic virus detection in clinical specimens. Emerg Infect Dis. 2015;21(1):48-57.
28. Conceição-Neto N, Zeller M, Lefrère H, De Bruyn P, Beller L, Deboutte W, Yinda CK, Lavigne $R$, Maes $P$, van Ranst $M$, et al. Modular approach to customise sample preparation procedures for viral metagenomics: a reproducible protocol for virome analysis. Sci Rep. 2015;5:16532.

29. Hall RJ, Wang J, Todd AK, Bissielo AB, Yen S, Strydom H, Moore NE, Ren X, Huang QS, Carter PE, et al. Evaluation of rapid and simple techniques for the enrichment of viruses prior to metagenomic virus discovery. J Virol Methods. 2014;195:194-204.

30. Li L, Deng X, Mee ET, Collot-Teixeira S, Anderson R, Schepelmann S, Minor PD, Delwart E. Comparing viral metagenomics methods using a highly multiplexed human viral pathogens reagent. J Virol Methods. 2015;213: 139-46.

31. Rosseel T, Ozhelvaci O, Freimanis G, Van Borm S. Evaluation of convenient pretreatment protocols for RNA virus metagenomics in serum and tissue samples. J Virol Methods. 2015:222:72-80.

32. Kim K-H, Bae J-W. Amplification methods bias metagenomic libraries of uncultured single-stranded and double-stranded DNA viruses. Appl Environ Microbiol. 2011;77(21):7663-8.

33. Sijmons S, Thys K, Corthout M, Van Damme E, Van Loock M, Bollen S, Baguet S, Aerssens J, van Ranst M, Maes P. A method enabling highthroughput sequencing of human cytomegalovirus complete genomes from clinical isolates. PLoS One. 2014;9(4):e95501.

34. Yokouchi H, Fukuoka Y, Mukoyama D, Calugay R, Takeyama H, Matsunaga T. Whole-metagenome amplification of a microbial community associated with scleractinian coral by multiple displacement amplification using phi29 polymerase. Environ Microbiol. 2006;8(7):1155-63.

35. van der Hoek L, Pyrc K, Jebbink MF, Vermeulen-Oost W, Berkhout RJM, Wolthers KC, Wertheim-van Dillen PME, Kaandorp J, Spaargaren J, Berkhout B. Identification of a new human coronavirus. Nat Med. 2004; 10(4):368-73.

36. Froussard P. A random-PCR method ( $r P C R)$ to construct whole cDNA library from low amounts of RNA. Nucleic Acids Res. 1992;20(11):2900.

37. Wang D, Urisman A, Liu Y-T, Springer M, Ksiazek TG, Erdman DD, Mardis ER, Hickenbotham M, Magrini V, Eldred J, et al. Viral discovery and sequence recovery using DNA microarrays. PLoS Biol. 2003;1(2):E2.

38. Lewandowska DW, Zagordi O, Zbinden A, Schuurmans MM, Schreiber $P$, Geissberger FD, Huder JB, Böni J, Benden C, Mueller NJ, et al. Unbiased metagenomic sequencing complements specific routine diagnostic methods and increases chances to detect rare viral strains. Diagn Microbiol Infect Dis. 2015;83(2):133-8.

39. Luk K-C, Berg MG, Naccache SN, Kabre B, Federman S, Mbanya D, Kaptué L, Chiu CY, Brennan CA, Hackett J. Utility of metagenomic next-generation sequencing for characterization of HIV and human pegivirus diversity. PLoS One. 2015;10(11):e0141723.

40. Abbas AA, Diamond JM, Chehoud C, Chang B, Kotzin JJ, Young JC, Imai I, Haas AR, Cantu E, Lederer DJ, et al. The perioperative lung transplant virome: torque teno viruses are elevated in donor lungs and show divergent dynamics in primary graft dysfunction. Am J Transplant. 2017; 17(5):1313-24.

41. Handley SA, Thackray LB, Zhao G, Presti R, Miller AD, Droit L, Abbink P, Maxfield LF, Kambal A, Duan E, et al. Pathogenic simian immunodeficiency virus infection is associated with expansion of the enteric virome. Cell. 2012; 151(2):253-66.

42. Allander T, Tammi MT, Eriksson M, Bjerkner A, Tiveljung-Lindell A, Andersson B. Cloning of a human parvovirus by molecular screening of respiratory tract samples. PNAS. 2005;102(36):12891-6.

43. Yun Z, Lewensohn-Fuchs I, Ljungman P, Vahlne A. Real-time monitoring of cytomegalovirus infections after stem cell transplantation using the TaqMan polymerase chain reaction assays. Transplantation. 2000;69(8):1733-6.

44. Tapparel C, Cordey S, Van Belle S, Turin L, Lee WM, Regamey N, Meylan P, Muhlemann K, Gobbini F, Kaiser L. New molecular detection tools adapted to emerging rhinoviruses and enteroviruses. J Clin Microbiol. 2009;47(6): 1742-9.

45. Heim A, Ebnet C, Harste G, Pring-Akerblom P. Rapid and quantitative detection of human adenovirus DNA by real-time PCR. J Med Virol. 2003; 70(2):228-39.

46. Berger C, Day P, Meier G, Zingg W, Bossart W, Nadal D. Dynamics of Epstein-Barr virus DNA levels in serum during EBV-associated disease. J Med Virol. 2001;64(4):505-12.

47. Huber M, Fischer M, Misselwitz B, Manrique A, Kuster H, Niederost B, Weber $\mathrm{R}$, von Wyl V, Gunthard HF, Trkola A. Complement lysis activity in 
autologous plasma is associated with lower viral loads during the acute phase of HIV-1 infection. PLoS Med. 2006;3(11):e441.

48. Dobin A, Davis CA, Schlesinger F, Drenkow J, Zaleski C, Jha S, Batut P, Chaisson M, Gingeras TR. STAR: ultrafast universal RNA-seq aligner. Bioinformatics. 2013;29(1):15-21.

49. Dobin A, Gingeras TR. Mapping RNA-seq reads with STAR. Curr Protoc Bioinformatics. 2015;51:11 14 11-9.

50. Camacho C, Coulouris G, Avagyan V, Ma N, Papadopoulos J, Bealer K, Madden TL. BLAST+: architecture and applications. BMC Bioinfor. 2009;10:421.

51. R Development Core Team. R: a language and environment for statistical computing. Vienna: R Foundation for Statistical Computing; 2005.

52. Mee ET, Preston MD, Minor PD, Schepelmann S, Participants CS. Development of a candidate reference material for adventitious virus detection in vaccine and biologicals manufacturing by deep sequencing. Vaccine. 2016;34(17):2035-43

53. Castro-Mejía JL, Muhammed MK, Kot W, Neve H, Franz CMAP, Hansen LH, Vogensen FK, Nielsen DS. Optimizing protocols for extraction of bacteriophages prior to metagenomic analyses of phage communities in the human gut. Microbiome. 2015;3(1):64.

54. de Vries M, Oude Munnink BB, Deijs M, Canuti M, Koekkoek SM, Molenkamp R, Bakker M, Jurriaans S, van Schaik BDC, Luyf AC, et al. Performance of VIDISCA-454 in feces-suspensions and serum. Viruses. 2012;4(8):1328-34.

55. Petty TJ, Cordey S, Padioleau I, Docquier M, Turin L, Preynat-Seauve O, Zdobnov EM, Kaiser L. Comprehensive human virus screening using highthroughput sequencing with a user-friendly representation of bioinformatics analysis: a pilot study. J Clin Microbiol. 2014;52(9):3351-61.

\section{Submit your next manuscript to BioMed Central} and we will help you at every step:

- We accept pre-submission inquiries

- Our selector tool helps you to find the most relevant journal

- We provide round the clock customer support

- Convenient online submission

- Thorough peer review

- Inclusion in PubMed and all major indexing services

- Maximum visibility for your research

Submit your manuscript at www.biomedcentral.com/submit 